\title{
Low-dose hydrocortisone in patients with cirrhosis and septic shock: a randomized controlled trial
}

\author{
Yaseen M. Arabi MD, Abdulrahman Aljumah MD, Ousama Dabbagh MD, \\ Hani M. Tamim PhD, Asgar H. Rishu MBBS, Abdulmajeed Al-Abdulkareem MD, \\ Bandar Al Knawy MD, Ali H. Hajeer PhD, Waleed Tamimi PhD, Antoine Cherfan PharmD \\ Previously published at www.cmaj.ca
}

\section{ABSTRACT}

Background: Recent studies have reported a high prevalence of relative adrenal insufficiency in patients with liver cirrhosis. However, the effect of corticosteroid replacement on mortality in this high-risk group remains unclear. We examined the effect of low-dose hydrocortisone in patients with cirrhosis who presented with septic shock.

Methods: We enrolled patients with cirrhosis and septic shock aged 18 years or older in a randomized double-blind placebo-controlled trial. Relative adrenal insufficiency was defined as a serum cortisol increase of less than $250 \mathrm{nmol} / \mathrm{L}$ or $9 \mu \mathrm{g} / \mathrm{dL}$ from baseline after stimulation with $250 \mu \mathrm{g}$ of intravenous corticotropin. Patients were assigned to receive $50 \mathrm{mg}$ of intravenous hydrocortisone or placebo every six hours until hemodynamic stability was achieved, followed by steroid tapering over eight days. The primary outcome was 28-day all-cause mortality.

Results: The trial was stopped for futility at interim analysis after 75 patients were enrolled. Relative adrenal insufficiency was diagnosed in $76 \%$ of patients. Compared with the placebo group $(n=36)$, patients in the hydrocortisone group ( $n=39$ ) had a significant reduction in vasopressor doses and higher rates of shock reversal (relative risk [RR] $1.58,95 \%$ confidence interval $[\mathrm{Cl}] 0.98-2.55, p=0.05$ ). Hydrocortisone use was not associated with a reduction in 28-day mortality (RR 1.17, 95\% Cl 0.92-1.49, $p=0.19$ ) but was associated with an increase in shock relapse (RR 2.58 $95 \% \mathrm{Cl} 1.04-6.45, p=0.03)$ and gastrointestinal bleeding (RR 3.00, 95\% Cl 1.08-8.36, $p=0.02$ ).

Interpretation: Relative adrenal insufficiency was very common in patients with cirrhosis presenting with septic shock. Despite initial favourable effects on hemodynamic parameters, hydrocortisone therapy did not reduce mortality and was associated with an increase in adverse effects. (Current Controlled Trials registry no. ISRCTN99675218.)

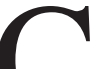
irrhosis is a leading cause of death worldwide, ${ }^{1}$ often with septic shock as the terminal event. ${ }^{2-9}$ Relative adrenal insufficiency shares similar features of distributive hyperdynamic shock with both cirrhosis and sepsis $^{10,11}$ and increasingly has been reported to coexist with both conditions. ${ }^{11,12}$ The effect of low-dose hydrocortisone therapy on survival of critically ill patients in general with septic shock remains controversial, with conflicting results from randomized controlled trials ${ }^{13-17}$ and meta-analyses..$^{18,19}$ The effect of hydrocortisone therapy on mortality among patients with cirrhosis, who are known to be a group at high risk for relative adrenal insufficiency, has not been studied and hence was the objective of our study.

\section{Methods}

\section{Setting}

The study was conducted in a 900-bed, tertiary care academic hospital. Patients with cirrhosis who present with septic shock are admitted to the 21-bed medical-surgical intensive care unit (ICU), which is run as a closed unit around the clock by in-house certified specialists in critical care. ${ }^{20} \mathrm{~A}$ multidisciplinary team of hepatologists, gastroenterologists and transplant surgeons coordinate the care of patients who have cirrhosis with the admitting intensivists.

\section{Study design}

Consecutive patients aged 18 years or older with liver cirrhosis who presented with septic shock were eligible within 72 hours of the onset of hypotension for this randomized doubleblind placebo-controlled trial. The study was approved by the Institutional Review Board of King Abdulaziz Medical City, registered at the Current Controlled Trials registry and conducted from April 2004 to October 2007. Definitions and exclusion criteria are described in Appendix 1, available at www.cmaj.ca/cgi/content/full/cmaj.090707/DC1.

\section{Randomization and interventions}

After obtaining consent, enrolled patients underwent a corticotropin stimulation test and randomization. Blood samples were drawn for baseline serum levels of cortisol, corticotropin, interleukin- 6 and tumour necrosis factor- $\alpha$,

From the Departments of Intensive Care Medicine (Arabi, Dabbagh, Rishu, Cherfan), Hepatobiliary Sciences (Aljumah, Al-Abdulkareem), Epidemiology and Biostatistics (Tamim), Medicine (Al Knawy) and Pathology and Laboratory Medicine (Hajeer, Tamimi), King Abdulaziz Medical City and King Saud Bin Abdulaziz University for Health Sciences, Riyadh, Saudi Arabia

CMAJ 2010. DOI:10.1503/cmaj.090707 
followed by administration of $250 \mu \mathrm{g}$ of intravenous corticotropin (Synacthen, Alliance Pharmaceuticals, United Kingdom). After 60 minutes, another blood sample was obtained for serum cortisol level. Laboratory personnel were blinded to the treatment allocation. The results of the corticotropin stimulation test and of tests for interleukin-6 and tumour necrosis factor- $\alpha$ were blinded to both the treating physicians and study investigators.

Randomization was performed by a central pharmacy using consecutive sealed envelopes and based on computer-generated random allocation in blocks to one of two arms in which participants received intravenous bolus injections every six hours of $5 \mathrm{~mL}$ of normal saline containing $50 \mathrm{mg}$ of hydrocortisone or normal saline (placebo). The two interventions were indiscernible. Patients as well as medical, nursing and clinical pharmacist staff remained blinded to the allocated therapy throughout the study. The full dose of the study drug was continued until shock resolution, which was defined as blood pressure stability (i.e., mean arterial pressure $>65 \mathrm{~mm} \mathrm{Hg}$ ) without vasopressors for 24 hours. The six-hourly dose was then reduced by $1 \mathrm{~mL}$ every two days until discontinuation. If the mean arterial pressure remained above $65 \mathrm{~mm} \mathrm{Hg}$ for more than 24 hours without vasopressors after complete cessation of the study drug, this was considered an end point for the intervention. However, if hypotension recurred during weaning, the dose was increased to full dosage again. If hypotension recurred after 24 hours of complete cessation of the study drug, the decision to use hydrocortisone or not as open label was left to the discretion of the treating physician.

\section{Management in the ICU and cointerventions}

All patients received hemodynamic monitoring and management, laboratory testing, antimicrobial therapy and stress-ulcer prophylaxis using a standardized protocol. Hemodynamic support followed the early goal-directed therapy protocol of Rivers and colleagues. ${ }^{21}$ Norepinephrine was the vasopressor of choice, and meropenem was the empiric antibiotic of choice unless indicated otherwise by cultures and clinical setting. All patients received histamine $\mathrm{H}_{2}$-receptor antagonists or proton pump inhibitors for stress-ulcer prophylaxis.

\section{Outcomes}

The primary outcome was 28-day all-cause mortality. Secondary outcomes included ICU-specific and hospital-specific mortality, mean arterial pressure, vasopressor doses, shock reversal, vasopressor-free days, mechanical ventilation-free days and renal replacement-free days (during the first 28 study days). We documented length of stay in ICU for ICU survivors and length of stay in hospital for hospital survivors. We documented the occurrence of the following potentially intervention-related side effects: severe hyperglycemia (> $10 \mathrm{mmol} / \mathrm{L}$ or $>180 \mathrm{mg} / \mathrm{dL}$ ), shock relapse (i.e., hypotension recurrence during weaning or within seven days of total discontinuation of the study drug), arrhythmia, gastrointestinal bleeding, bacteremia and ventilator-associated pneumonia (as defined by the National Nosocomial Infections Surveillance System). ${ }^{22}$

\section{Cortisol, corticotropin and cytokine assays}

Cortisol was measured by an ARCHITECT analyzer (Abbott, Chicago, USA) using a chemiluminescent immunoassay. Corticotropin was measured using the autochemiluminescence system IMMULITE 2000 (Siemens Medical Solutions Diagnostics, New York, USA). Relative adrenal insufficiency was defined as a cortisol increase of less than $250 \mathrm{nmol} / \mathrm{L}$ or $9 \mu \mathrm{g} / \mathrm{dL}$ from baseline after corticotropin stimulation. ${ }^{13}$ Samples for tumour necrosis factor- $\alpha$ and interleukin- 6 were obtained on days one, three and seven, stored at $-80^{\circ} \mathrm{C}$ and assayed using a solid-phase chemiluminescent enzyme immunoassay (Immunlite, EURO/DPC Ltd., Gwynedd, UK) according to the manufacturer's specifications. The lowest detectable limit for interleukin- 6 was $5 \mathrm{pg} / \mathrm{mL}$, and for tumour necrosis factor- $\alpha$, it was $1.7 \mathrm{pg} / \mathrm{mL}$.

\section{Statistical analysis}

Statistical analyses were performed on an intention-to-treat basis. Based on an estimated baseline 28-day mortality of $90 \%$ and an estimated absolute risk reduction of 20\%, 75 patients were required in each group using a two-sided type I error of 5\% and a power of $80 \%$. Stratified analyses were performed for several variables and were tested for interaction. Detailed descriptions of sample size calculation and statistical analyses, as well as study protocol, are available in Appendices 1 and 2 at www.cmaj.ca/cgi/content/full/cmaj.090707 /DC1. A post-hoc futility analysis was carried out to calculate the conditional power of the study under the following three alternative assumptions: first, that the treatment effect size expected in future data would be the same as that in the original study design; second, that it would be the same as the trend in the data thus far; and third, that it would be zero (i.e., that the null hypothesis is true). ${ }^{23}$

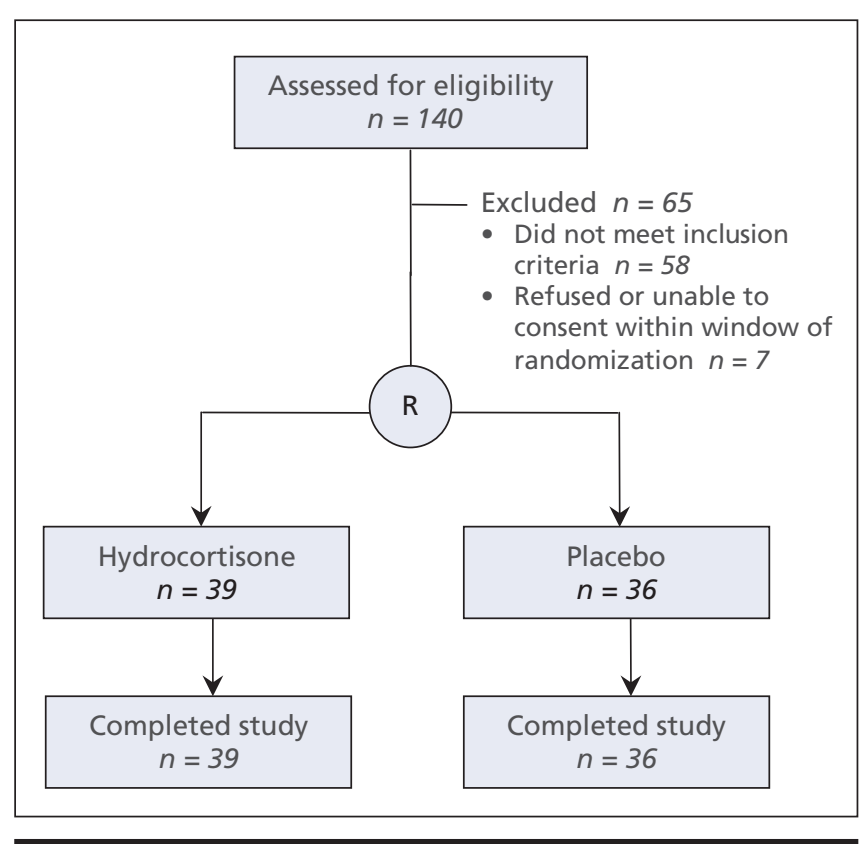

Figure 1: Flow of patients through the trial. 


\section{Results}

\section{Study description}

Of 140 patients screened, 75 were enrolled and randomly allocated (Figure 1). Sixty patients (80\%) were enrolled within 24 hours after the onset of shock and $71(95 \%)$ within 48 hours. For one patient, blinding was opened at the request of the primary physician, but the allocated therapy (placebo) was continued as planned per study protocol. The investigators performed a planned interim analysis after randomly allocating 75 patients and found a trend toward excess 28 -day mortality with hydrocortisone therapy compared with placebo (33 [85\%] v. 26 [72\%]; relative risk $[\mathrm{RR}] 1.17,95 \%$ confidence interval $[\mathrm{CI}]$ 0.92-1.49, $p=0.19$ ). The investigators stopped the trial for futility because the $95 \%$ CI for the RR for the primary outcome excluded the anticipated RR of 0.78 with hydrocortisone ${ }^{24}$ Post-hoc futility analyses yielded very low conditional powers of $3.4 \%$ for the first assumption described earlier, $0.00 \%$ for the second and $0.01 \%$ for the third. These results indicate that it is highly unlikely that a significant treatment benefit would be evident even if the trial were completed to the targeted sample size.

\section{Patient characteristics}

Baseline characteristics, including use of etomidate, were similar in the two groups (Table 1). Cortisol levels were not different at baseline and increased modestly after corticotropin stimulation to similar levels in the two groups. Overall, $76 \%$ of patients had a cortisol increase of less than $250 \mathrm{nmol} / \mathrm{L}(9 \mu \mathrm{g} / \mathrm{dL})$ from baseline (i.e., were "nonresponders"), with similar proportions in the two groups.

Table 1: Baseline characteristics at enrolment of patients in the hydrocortisone and placebo groups

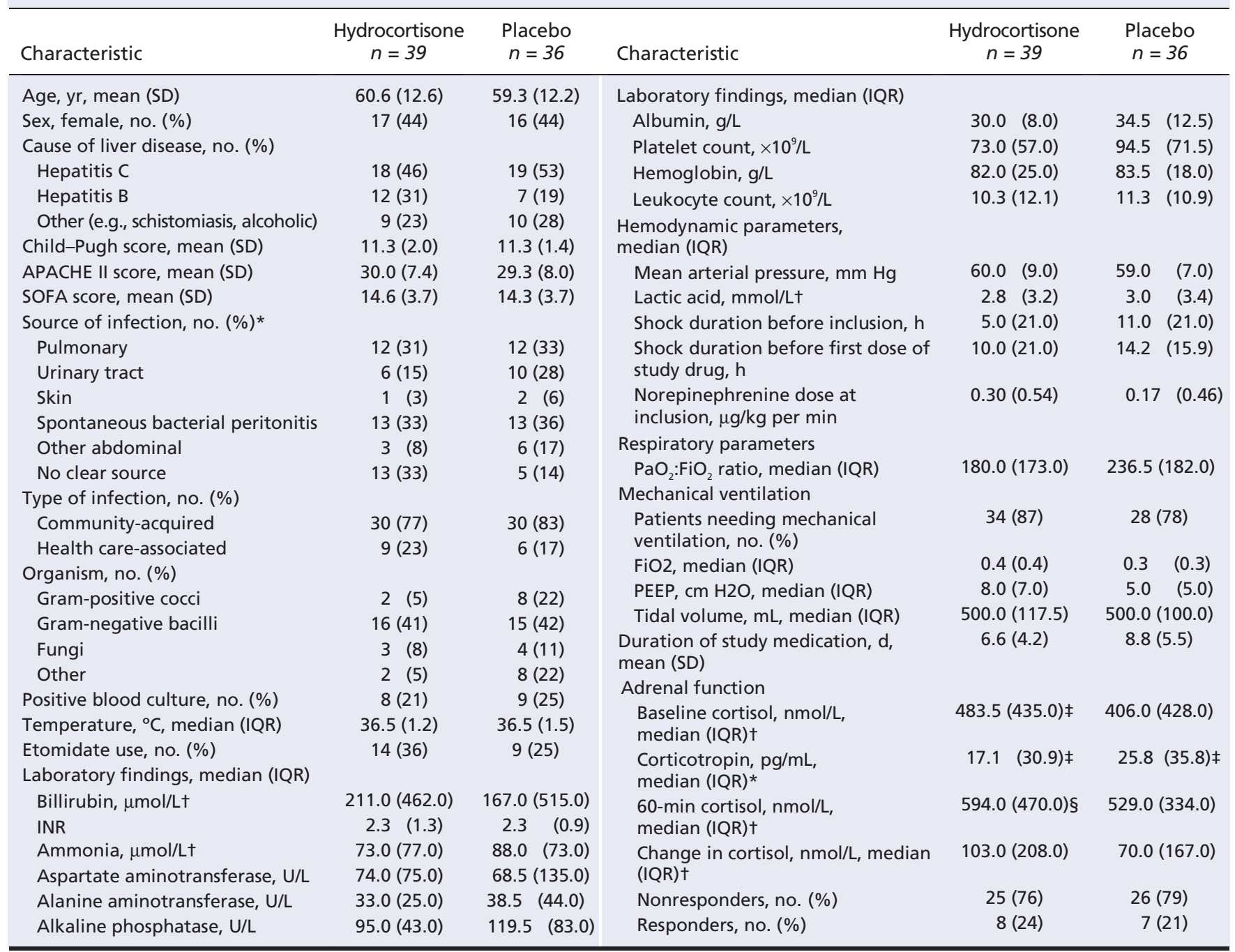

Note: APACHE II = Acute Physiology and Chronic Health Evaluation II, INR = international normalized ratio, IQR = interquartile range, PaO $\mathrm{F}_{2} \mathrm{FiO}{ }_{2}$ ratio $=$ ratio of partial pressure of oxygen to fraction of inspired oxygen, PEEP = positive expiratory end pressure, SD = standard deviation, SOFA = sequential organ failure assessment.

*Total of values may exceed $100 \%$ because some patients had more than one source of infection.

tTo convert bilirubin to $\mathrm{mg} / \mathrm{dL}$, divide value by 17.1 . To convert ammonia to $\mu \mathrm{g} / \mathrm{dL}$, divide value by 0.587 . To convert lactic acid to mg/dL, divide value by 0.111 . To convert cortisol to $\mu \mathrm{g} / \mathrm{dL}$, divide value by 27.59 . To convert corticotropin to $\mathrm{pmol} / \mathrm{L}$, multiply value by 0.22 .

¥Missing one value (sample not withdrawn).

§Missing six values (samples not withdrawn).

ףMissing three values (samples not withdrawn). 
Table 2: Parameters of intensive care unit (ICU) management and co-interventions

\begin{tabular}{|c|c|c|c|}
\hline Variable & $\begin{array}{c}\text { Hydrocortisone, } \\
\text { mean }(S D)^{*} \\
n=39\end{array}$ & $\begin{array}{c}\text { Placebo, } \\
\text { mean (SD)* } \\
n=36\end{array}$ & $p$ value \\
\hline \multicolumn{4}{|c|}{$\begin{array}{l}\text { Central venous pressure, } \\
\mathrm{mm} \mathrm{Hg}\end{array}$} \\
\hline Day 1 & $14.7(6.5)$ & $16.1(5.9)$ & 0.36 \\
\hline Day 3 & $14.1(4.8)$ & $13.9(5.5)$ & 0.89 \\
\hline \multicolumn{4}{|c|}{$\begin{array}{l}\text { Intra-abdominal pressure, } \\
\mathrm{mm} \mathrm{Hg}\end{array}$} \\
\hline Day 1 & $15.1(3.5)$ & $15.5(5.8)$ & 0.74 \\
\hline Day 3 & $13.7(3.5)$ & $17.2(6.9)$ & 0.01 \\
\hline Paracentesis, no. (\%) & $10(26)$ & $13(36)$ & 0.33 \\
\hline \multicolumn{4}{|c|}{ Venous oxygen saturation, $\%$} \\
\hline Day 1 & $77.1(11.1)$ & $75.7 \quad(9.8)$ & 0.59 \\
\hline Day 3 & 77.7 (8.8) & $75.0(10.6)$ & 0.28 \\
\hline \multicolumn{4}{|l|}{ Fluid intake, $\mathrm{mL}$} \\
\hline Day 1 & $4126.6(2554.0)$ & $3967.9(2583.4)$ & 0.79 \\
\hline Day 3 & $2950.9(1925.3)$ & 3007.1 (1812.9) & 0.90 \\
\hline \multicolumn{4}{|l|}{ Fluid output, mL } \\
\hline Day 1 & $1260.1(1616.9)$ & $1025.9(1551.4)$ & 0.52 \\
\hline Day 3 & $2192.3(2484.1)$ & $1638.9(1783.6)$ & 0.30 \\
\hline \multicolumn{4}{|l|}{$\begin{array}{l}\text { Packed red blood cell } \\
\text { transfusion, units }\end{array}$} \\
\hline Day 1 & $0.8(1.7)$ & $0.6(1.0)$ & 0.56 \\
\hline Day 3 & $0.4(1.3)$ & $0.2(1.1)$ & 0.46 \\
\hline \multicolumn{4}{|c|}{ Fresh frozen plasma, units } \\
\hline Day 1 & $2.7(3.7)$ & $1.9(2.6)$ & 0.26 \\
\hline Day 3 & $1.5(3.0)$ & $1.2(2.2)$ & 0.67 \\
\hline \multicolumn{4}{|l|}{ Platelets, units } \\
\hline Day 1 & $0.9(2.6)$ & $1.2(2.6)$ & 0.62 \\
\hline Day 3 & $1.0(3.1)$ & $0.5(1.8)$ & 0.43 \\
\hline \multicolumn{4}{|l|}{ Cryoprecipitate, units } \\
\hline Day 1 & $0.8(2.7)$ & $0.6(2.3)$ & 0.72 \\
\hline Day 3 & $0.3(1.7)$ & $0.0(0.0)$ & 0.28 \\
\hline \multicolumn{4}{|l|}{ Albumin $5 \%, \mathrm{~mL}$} \\
\hline Day 1 & $179.5(519.2)$ & $111.2(263.5)$ & 0.47 \\
\hline Day 3 & $84.9(218.3)$ & $75.8(169.2)$ & 0.85 \\
\hline \multicolumn{4}{|l|}{ Albumin $20 \%, \mathrm{~mL}$} \\
\hline Day 1 & $38.5(104.2)$ & $69.4(109.1)$ & 0.21 \\
\hline Day 3 & $51.4(101.1)$ & 79.7 (127.9) & 0.31 \\
\hline \multicolumn{4}{|c|}{ Peak airway pressure, $\mathrm{cm} \mathrm{H}_{2} \mathrm{O}$} \\
\hline Day 1 & $28.4(6.8)$ & $28.5(7.5)$ & 0.95 \\
\hline Day 3 & $27.6(5.4)$ & $29.1(7.1)$ & 0.46 \\
\hline \multicolumn{4}{|c|}{ Mean airway pressure, $\mathrm{cm} \mathrm{H}_{2} \mathrm{O}$} \\
\hline Day 1 & $15.5(5.5)$ & $13.7(5.9)$ & 0.29 \\
\hline Day 3 & $14.2(4.5)$ & $14.3(4.6)$ & 0.96 \\
\hline \multicolumn{4}{|l|}{ PEEP, $\mathrm{cm} \mathrm{H}_{2} \mathrm{O}$} \\
\hline Day 1 & $8.9(5.2)$ & $7.3(3.4)$ & 0.18 \\
\hline Day 3 & $8.8(3.0)$ & $7.6(3.1)$ & 0.20 \\
\hline $\begin{array}{l}\text { Renal replacement } \\
\text { therapy, no. (\%) }\end{array}$ & $25(64)$ & $27(75)$ & 0.31 \\
\hline
\end{tabular}

Note: $\mathrm{PEEP}=$ positive expiratory end pressure, SD = standard deviation. *Unless otherwise indicated.

\section{ICU and cointerventions}

Clinical parameters, including those related to fluid status and ventilatory pressures, and cointerventions, including transfusion requirements, were similar in the two groups (Table 2).

\section{Mortality}

There was no significant difference between the hydrocortisone and placebo groups in 28-day mortality (33 [85\%] v. 26 [72\%], RR $1.17,95 \%$ CI $0.92-1.49, p=0.19$ ) or in ICU or hospital mortality (Table 3). Kaplan-Meier curves for survival at 28 days (Figure 2) also showed no significant difference $(p=0.50)$. Moreover, there was no significant interaction between response to corticotropin and assigned treatment with respect to 28-day mortality $(p=0.39)$.

\section{Hemodynamic response}

Hydrocortisone was associated with significant improvement in mean arterial pressure and with reduction in norepinephrine doses (Appendix 3, available at www.cmaj.ca/cgi/content /full/cmaj.090707/DC1) and an increase in shock reversal compared with placebo (24 [62\%] v. 14 [39\%], RR 1.58, 95\% CI $0.98-2.55, p=0.05)$. However, during and after tapering of the study drug, shock relapsed more often in the hydrocortisone group (13 [34\%] v. 5 [14\%], RR 2.58, 95\% CI 1.04 $6.45, p=0.03)$. When stratified by the response to corticotropin, hemodynamic improvement was observed in nonresponders and not in responders (Appendix 3, panels C, $\mathrm{D}, \mathrm{E}$ and $\mathrm{F}$, available at www.cmaj.ca/cgi/content/full/cmaj .090707/DC1).

\section{Other outcomes}

There was no difference between the two groups in mechanical ventilation-free days, renal replacement therapy-free days, length of stay in ICU or length of stay in hospital (Table 3). Hydrocortisone was associated with higher rates of severe hyperglycemia and with a significant increase in the risk of gastrointestinal bleeding (RR 3.00, 95\% CI 1.08-8.36).

\section{Stratified analyses}

With respect to 28-day mortality, there was no significant interaction between the assigned treatment and use of etomidate, duration of shock before randomization, duration of treatment with the study drug, Acute Physiology and Chronic Health Evaluation II score, or achievement of hemodynamic targets.

\section{Cytokine levels}

There was progressive reduction in the levels of interleukin-6 and tumour necrosis factor- $\alpha$ in the hydrocortisone and placebo groups. A significant difference in these levels between the hydrocortisone and placebo groups was seen only for tumour necrosis factor- $\alpha$ and only at day seven $(15.6 \pm 13.6 \mathrm{pg} / \mathrm{ml}$ v. $25.9 \pm 18.0 \mathrm{pg} / \mathrm{mL}, p=0.03)$.

\section{Interpretation}

Relative adrenal insufficiency was very common among patients with cirrhosis presenting with septic shock. Hydrocor- 
tisone therapy resulted in a significant hemodynamic improvement, especially in nonresponders to corticotropin. Despite these initial favourable hemodynamic effects, hydrocortisone therapy did not reduce mortality and was associated with an increase in shock relapse and gastrointestinal bleeding.

Corticosteroid therapy in septic shock has fallen in and out of favour over the last few decades. ${ }^{25,26}$ Annane and colleagues ${ }^{13}$ reported a significant reduction in mortality with hydrocortisone therapy among patients with septic shock - a finding that led to the recommendation of hydrocortisone as a standard therapy in the Surviving Sepsis Campaign. ${ }^{27}$ Similar results have been reported in other studies ${ }^{14-16}$ and a metaanalysis. ${ }^{18}$ However, the results of the study by Annane and colleagues were considered borderline because they were achieved only after statistical adjustment ${ }^{28}$ and because crude in-hospital mortality was higher among responders to corticotropin who received hydrocortisone. More recently, the Corticosteroid Therapy of Septic Shock (CORTICUS) study showed that corticosteroids had no effect on 28-day mortality, even among nonresponders. ${ }^{17}$

Relative adrenal insufficiency has recently been described in $62 \%-80 \%$ of heterogeneous groups of patients with liver disease. ${ }^{11,12,29,30}$ Our study shows a prevalence of relative adrenal insufficiency reaching $76 \%$ in a homogenous group of patients with cirrhosis presenting with septic shock. Several potential mechanisms have been postulated, including adrenal exhaustion, ${ }^{31}$ inhibition of cortisol synthesis by tumour necrosis factor- $\alpha^{32}$ and, less likely, adrenal hemorrhage. ${ }^{29}$

Despite this high prevalence of relative adrenal insufficiency, our study showed no survival benefit with hydrocortisone therapy, although hemodynamic parameters improved significantly. There are several potential explanations. First, it has been suggested that the benefit observed by Annane and colleagues but not in the CORTICUS study was related to the shorter randomization window ( 8 v. 72 hours). In our study, $80 \%$ of patients were enrolled within the first 24 hours after the onset of shock. Furthermore, we found no interaction between the assigned treatment and the duration of shock before randomization with respect to 28-day mortality.

Second, $33 \%$ of our patients had received etomidate, which is known to cause adrenal suppression. ${ }^{33}$ However, this proportion was not different in the CORTICUS study (26\% of patients) or the study by Annane and colleagues (24\% of patients). Furthermore, we found no interaction between the assigned treatment and etomidate use with respect to 28-day mortality.

Table 3: Outcomes among patients with cirrhosis and sepsis receiving low-dose hydrocortisone

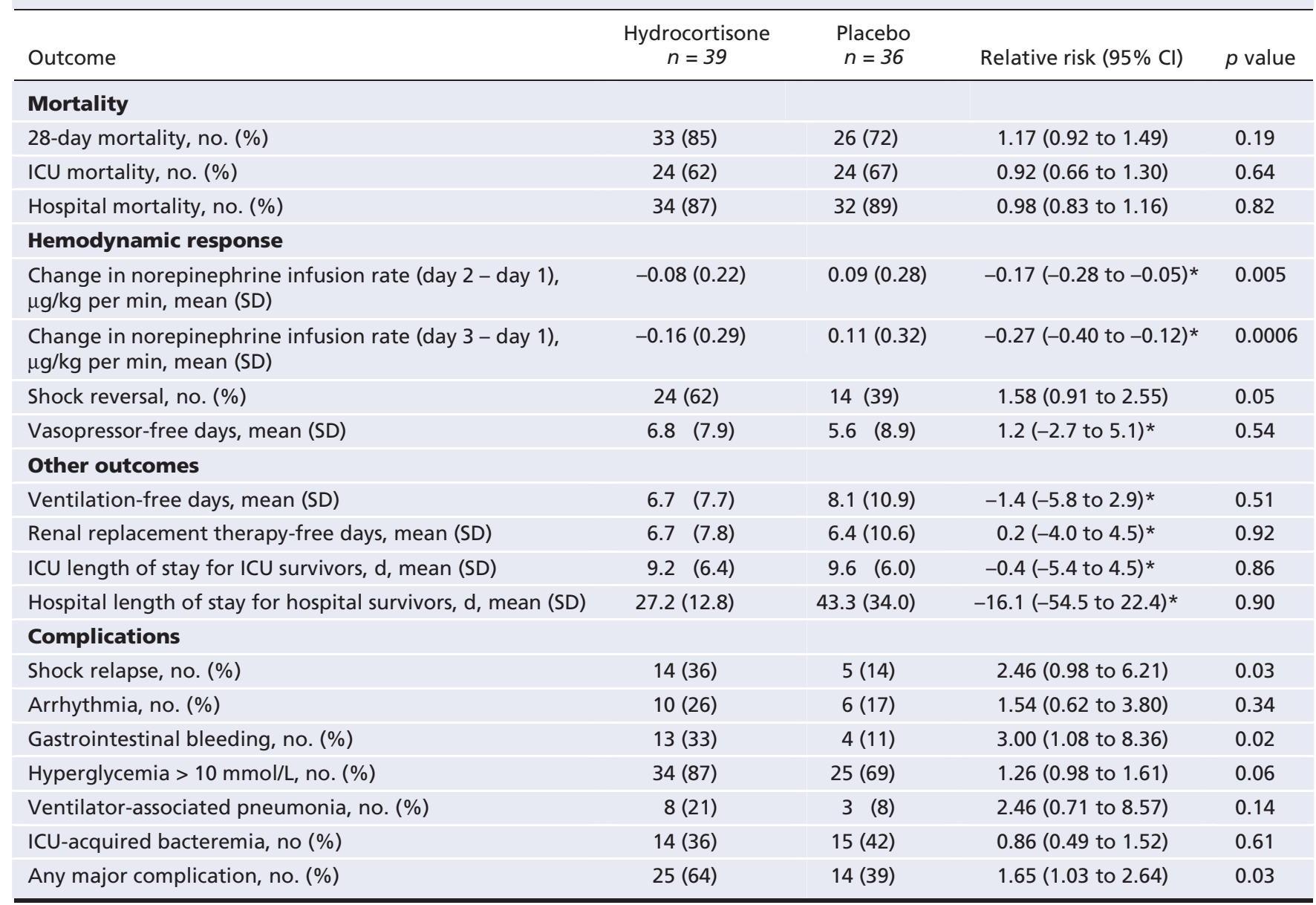

Note: $\mathrm{Cl}=$ confidence interval, $\mathrm{ICU}=$ intensive care unit, $\mathrm{SD}=$ standard deviation.

*Mean difference and $95 \% \mathrm{Cl}$. 


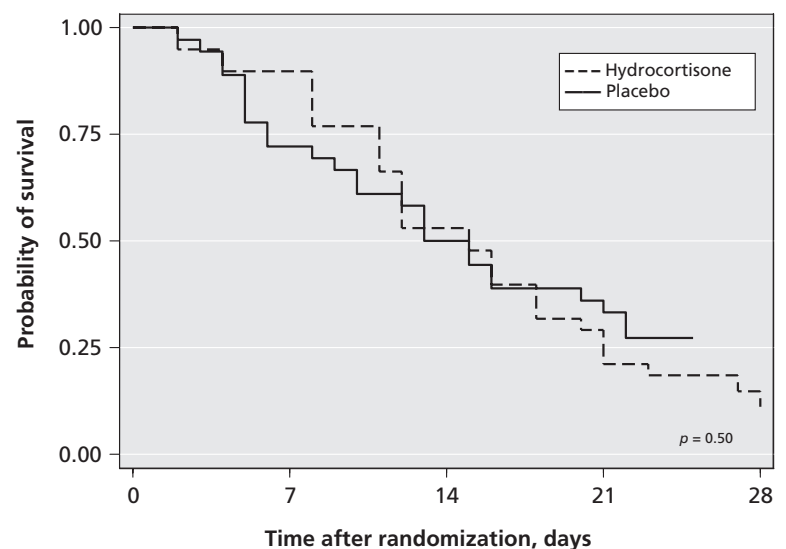

$\begin{array}{rr}\text { No. at risk } & \\ \text { Hydrocortisone } & 39 \\ \text { Placebo } & 36\end{array}$ 35

26

\section{0}

11

13

\section{4}

Figure 2: Kaplan-Meier survival curves for patients in the hydrocortisone and placebo groups.

Third, Annane and colleagues used fludrocortisone, whereas the CORTICUS study did not. However, cirrhosis is characterized by hyperaldosteronism, ${ }^{34}$ which is the basis for the use of aldosterone antagonists to treat ascites..$^{35}$ Additionally, the absorption of oral medications is unreliable in patients with cirrhosis, and a daily hydrocortisone dose of $200 \mathrm{mg}$, which was used in these trials, provides adequate mineralocorticoid activity. ${ }^{17}$

Fourth, we observed a significant increase in shock relapse after weaning hydrocortisone. This increase was surprising because of the relatively slow eight-day tapering protocol for hydrocortisone initiated 24 hours after hemodynamic stability was achieved. This protocol contrasts with cessation of corticosteroids after seven days by Annane and colleagues and tapering from day 5 to 11 in the CORTICUS study, regardless of hemodynamic status. In the CORTICUS trial, shock relapse was observed in $31 \%$ of the hydrocortisone group and $25 \%$ of the placebo group. However, since hydrocortisone was tapered in some patients while vasopressors were still required, these numbers may underestimate the hemodynamic deterioration due to steroid tapering. The very high mortality associated with relapse of shock may have mitigated any beneficial effects of hydrocortisone. Why did shock recur after tapering of hydrocortisone? It is possible that relative adrenal insufficiency is inherent in patients with cirrhosis and not a temporary sepsis-related phenomenon, and as such, a longer duration of therapy might be required. Alternatively, hydrocortisone therapy may have further suppressed the pituitaryadrenal axis, and thus tapering precipitated an adrenal crisis.

Fifth, use of low-dose (often called "stress-" or "physiologic-dose") hydrocortisone is not free of adverse effects. We observed a three-fold increase in gastrointestinal bleeding with very high associated mortality, which may have counteracted any potential benefit. Sixth, the low-dose hydrocortisone is not a simple hormone replacement therapy, but rather has clear immunomodulatory effects, as shown by the reduction in pro-inflammatory cytokines, which may alter the body's ability to mount an "appropriate" pro-inflammatory response and host defences. Seventh, relative adrenal insufficiency may be just a marker of illness. If so, hydrocortisone therapy would expose patients only to adverse effects, such as further adrenal suppression, gastrointestinal bleeding and immunosuppression. Finally, patients with cirrhosis and sepsis may constitute a special group that differs in physiology and severity from other ICU patients with sepsis and perhaps in response to hydrocortisone therapy.

The use of a corticotropin stimulation test before hydrocortisone therapy has been debated. A meta-analysis showed beneficial effects of steroid therapy in both responders and nonresponders to corticotropin, ${ }^{18}$ and the Surviving Sepsis Campaign considered the test "optional." ${ }^{27}$ However, our study does not support hydrocortisone therapy in cirrhosis without a corticotropin stimulation test because of lack of hemodynamic and survival benefits in responders.

The use of free rather than total serum cortisol levels has been suggested for the diagnosis of relative adrenal insufficiency because of dissociation between the levels of the total and the physiologically active free cortisol. ${ }^{36}$ However, recent guidelines have not recommended the routine use of free cortisol measurements because of lack of availability and lack of an established normal range in critically ill patients. ${ }^{19}$

\section{Strengths and limitations}

Strengths of our study included the randomized double-blind placebo-controlled design, intention-to-treat analysis, homogenous population, inclusion of steroid-naive patients and standardized ICU management. In addition, our protocolized slow tapering of the study drug after achieving predefined parameters of hemodynamic stability was more physiologically appropriate than use of a predefined schedule with abrupt cessation or tapering irrespective of hemodynamic status.

As a limitation, our study was a single-centre trial, which may affect its generalizability. Issues related to the length of our study's randomization window and to the use of etomidate are addressed earlier in the article.

\section{Conclusion}

Relative adrenal insufficiency is common in patients with cirrhosis presenting with septic shock. Hydrocortisone therapy was associated with hemodynamic improvement. However, it did not reduce mortality and was associated with an increase in shock relapse and gastrointestinal bleeding. Our results suggest a need for further multicentre randomized controlled trials, possibly using lower doses of hydrocortisone and for a longer duration.

\section{This article has been peer reviewed.}

Competing interests: Abdulmajeed Al-Abdulkareem is a member of the board of directors and the international advisory panel of King Faisal Specialist Hospital and Research Center, Riyadh, Saudi Arabia. Waleed Tamimi has received a research grant from King Abdulaziz City for Science and Technology, Riyadh, Saudi Arabia. Ousama Dabbagh has received research grants from Bristol Myer Squibb and Pfizer, and has served on the speaker bureau of Sanofi-aventis. No competing interests declared by the other authors.

Contributors: Yaseen Arabi, Abdulrahman Aljumah, Ousama Dabbagh, Abdulmajeed Al-Abdulkareem, Ali Hajeer and Waleed Tamimi were respon- 
sible for the conception and design of the study. Yaseen Arabi, Abdulrahman Aljumah, Ousama Dabbagh, Asgar Rishu, Abdulmajeed Al-Abdulkareem, Bandar Al Knawy, Ali Hajeer, Waleed Tamimi and Antoine Cherfan took part in the acquisition of data. Yaseen Arabi, Hani Tamim and Ali Hajeer were responsible for analysis and interpretation of data. Yaseen Arabi, Hani Tamim, Asgar Rishu and Ali Hajeer were responsible for drafting the manuscript. Yaseen Arabi, Abdulrahman Aljumah, Ousama Dabbagh, Abdulmajeed Al-Abdulkareem, Bandar Al Knawy, Ali Hajeer, Antoine Cherfan and Waleed Tamimi were in charge of critical revision of the manuscript for important intellectual content. Yaseen Arabi and Hani Tamim were responsible for statistical analysis. All of the authors approved the final version of the manuscript submitted for publication. Yaseen Arabi was the primary investigator, had full access to all of the data and takes responsibility for the integrity of the data and accuracy of the data analysis.

Acknowledgements: The authors acknowledge the following colleagues from King Abdulaziz Medical City for their participation in patient recruitment, in-services, screening for eligible patients and assistance in data collection: Dr. Abdullah A. Al-Shimemeri, Intensive Care Department; Dr. Ibrahim Traif, Department of Hepatobiliary Sciences; Dr. Abduljalil Alwan, Department of Hepatobiliary Sciences; Mr. Salim H. Kahoul RN, Intensive Care Department; Mrs. Riette J. Britts RN, Intensive Care Department; Dr. Sofia J. Syed MBBS, Intensive Care Department.

Funding: This study was funded by King Abdulaziz City for Science and Technology (grant no. LG-9-12).

\section{REFERENCES}

1. Hoyert DL, Kung HC, Smith BL. Deaths: preliminary data for 2003. Natl Vital Stat Rep 2005;53:1-48.

2. Vashist Y, Semela D, Dufour JF. Hyperdynamic circulation in liver cirrhosis: desensitization of vasoconstrictive receptors by $\mathrm{G}$ protein-coupled receptor kinases. Med Hypotheses 2004;62:82-5.

3. Newby DE, Hayes PC. Hyperdynamic circulation in liver cirrhosis: not peripheral vasodilatation but 'splanchnic steal.' QJM 2002;95:827-30.

4. Arkenau HT, Stichtenoth DO, Frolich JC, et al. Elevated nitric oxide levels in patients with chronic liver disease and cirrhosis correlate with disease stage and parameters of hyperdynamic circulation. Z Gastroenterol 2002;40:907-13.

5. Gaenzer H, Sturm W, Neumayr G, et al. Hyperdynamic circulation in liver cirrhosis: no evidence for peripheral vasodilation detected by ultrasound of the brachial artery. Am J Gastroenterol 2000;95:551-2.

6. Campillo B, Bories PN, Benvenuti C, et al. Serum and urinary nitrate levels in liver cirrhosis: endotoxemia, renal function and hyperdynamic circulation. $J$ Hepatol 1996;25:707-14

7. Li CP, Lee FY, Tsai YT, et al. Plasma interleukin-8 levels in patients with posthepatitic cirrhosis: relationship to severity of liver disease, portal hypertension and hyperdynamic circulation. J Gastroenterol Hepatol 1996;11:635-40.

8. Arabi Y, Ahmed QA, Haddad S, et al. Outcome predictors of cirrhosis patient admitted to the intensive care unit. Eur J Gastroenterol Hepatol 2004;16:333-9.

9. Arabi Y, Haddad S, Goraj R, et al. Assessment of performance of four mortality prediction systems in a Saudi Arabian intensive care unit. Crit Care 2002;6:166-74.

10. Bouachour G, Tirot $\mathrm{P}$, Varache $\mathrm{N}$, et al. Hemodynamic changes in acute adrenal insufficiency. Intensive Care Med 1994;20:138-41.

11. Marik PE, Gayowski T, Starzl TE. The hepatoadrenal syndrome: a common ye unrecognized clinical condition. Crit Care Med 2005;33:1254-9.

12. Zietz B, Lock G, Plach B, et al. Dysfunction of the hypothalamic-pituitary-glandular axes and relation to Child-Pugh classification in male patients with alcoholic and virus-related cirrhosis. Eur J Gastroenterol Hepatol 2003;15:495-501.

13. Annane D, Sebille V, Charpentier C, et al. Effect of treatment with low doses of hydrocortisone and fludrocortisone on mortality in patients with septic shock. JAMA 2002;288:862-71.

14. Bellissant E, Annane D. Effect of hydrocortisone on phenylephrine-mean arterial pressure dose-response relationship in septic shock. Clin Pharmacol Ther 2000;68:293-303.

15. Bollaert PE, Charpentier C, Levy B, et al. Reversal of late septic shock with supraphysiologic doses of hydrocortisone. Crit Care Med 1998;26:645-50.
16. Briegel J, Forst H, Haller M, et al. Stress doses of hydrocortisone reverse hyper dynamic septic shock: a prospective, randomized, double-blind, single-center study. Crit Care Med 1999;27:723-32.

17. Sprung CL, Annane D, Keh D, et al. Hydrocortisone therapy for patients with septic shock. N Engl J Med 2008;358:111-24.

18. Minneci PC, Deans KJ, Banks SM, et al. Meta-analysis: the effect of steroids on survival and shock during sepsis depends on the dose. Ann Intern Med 2004;141: 47-56.

19. Marik PE, Pastores SM, Annane D, et al. Recommendations for the diagnosis and management of corticosteroid insufficiency in critically ill adult patients: consensus statements from an international task force by the American College of Critical Care Medicine. Crit Care Med 2008;36:1937-49.

20. Arabi Y, Alshimemeri A, Taher S. Weekend and weeknight admissions have the same outcome of weekday admissions to an intensive care unit with onsite intensivist coverage. Crit Care Med 2006;34:605-11.

21. Rivers E, Nguyen B, Havstad S, et al. Early goal-directed therapy in the treatment of severe sepsis and septic shock. N Engl J Med 2001;345:1368-77.

22. Emori TG, Culver DH, Horan TC, et al. National nosocomial infections surveillance system (NNIS): description of surveillance methods. Am J Infect Control 1991; 19:19-35.

23. Lachin JM. A review of methods for futility stopping based on conditional power. Stat Med 2005;24:2747-64.

24. Pocock SJ. Current controversies in data monitoring for clinical trials. Clin Trials 2006;3:513-21.

25. Lefering R, Neugebauer EA. Steroid controversy in sepsis and septic shock: a meta-analysis. Crit Care Med 1995;23:1294-303.

26. Bone RC, Fisher CJ Jr, Clemmer TP, et al. A controlled clinical trial of high-dose methylprednisolone in the treatment of severe sepsis and septic shock. $N$ Engl J Med 1987;317:653-8.

27. Dellinger RP, Carlet JM, Masur H, et al. Surviving Sepsis Campaign guidelines for management of severe sepsis and septic shock. Crit Care Med 2004;32:858-73.

28. Finfer S. Corticosteroids in septic shock. N Engl J Med 2008;358:188-90.

29. Harry R, Auzinger G, Wendon J. The clinical importance of adrenal insufficiency in acute hepatic dysfunction. Hepatology 2002;36:395-402

30. Marik PE. Adrenal-exhaustion syndrome in patients with liver disease. Intensive Care Med 2006;32:275-80.

31. Moran JL, Chapman MJ, O'Fathartaigh MS, et al. Hypocortisolaemia and adrenocortical responsiveness at onset of septic shock. Intensive Care Med 1994;20:489-95.

32. Jaattela M, Ilvesmaki V, Voutilainen R, et al. Tumor necrosis factor as a potent inhibitor of adrenocorticotropin-induced cortisol production and steroidogenic P450 enzyme gene expression in cultured human fetal adrenal cells. Endocrinology 1991;128:623-9.

33. Absalom A, Pledger D, Kong A. Adrenocortical function in critically ill patients $24 \mathrm{~h}$ after a single dose of etomidate. Anaesthesia 1999;54:861-7.

34. Trevisani F, Bernardi M, De Palma R, et al. Circadian variation in renal sodium and potassium handling in cirrhosis. The role of aldosterone, cortisol, sympathoadrenergic tone, and intratubular factors. Gastroenterology 1989;96:1187-98.

35. Fernandez-Esparrach G, Guevara M, Sort P, et al. Diuretic requirements after therapeutic paracentesis in non-azotemic patients with cirrhosis. A randomized doubleblind trial of spironolactone versus placebo. J Hepatol 1997;26:614-20.

36. Hamrahian AH, Oseni TS, Arafah BM. Measurements of serum free cortisol in critically ill patients. N Engl J Med 2004;350:1629-38.

\section{Correspondence to: Dr. Yaseen M. Arabi, King Saud Bin,} Abdulaziz University for Health Sciences, King Abdulaziz Medical City, PO Box 22490, Intensive Care Department, MC 1425, Riyadh, 11426, Saudi Arabia; yaseenarabi@yahoo.com; icul@ngha.med.sa

Editors note: For the study protocol pertaining to this article, please see Appendix 2, available at www.cmaj.ca/cgi/content /full/cmaj.090707/DC1. 